\title{
When Online Exchanges Byte: An Examination of the Policy Environment Governing Cyberbullying at the University Level
}

Chantal Faucher, Margaret Jackson, and Wanda Cassidy

Simon Fraser University

\begin{abstract}
This article reports on findings from a scan of 465 policies relevant to the handling of cyberbullying in 74 Canadian universities. It first assesses the commonalities and differences in the policies. Second, it considers how their various lenses-a human rights perspective versus a student conduct perspective, for instance-can affect the directions and outcomes of university responses. The majority of the policies reviewed were codes of student conduct and discipline, policies on electronic communication, and policies on harassment and discrimination. Most of the policies outlined complaint procedures and possible sanctions, but relatively few addressed prevention of unacceptable behaviours. Only about a third made reference to "cyber" behaviours, suggesting that the university policy environment is not current with the information and communication technologies that permeate the daily lives of university students and faculty.
\end{abstract}

\section{Résumé}

Cet article rapporte les résultats d'un survol de 465 politiques ayant trait à la cyberintimidation et provenant de 74 universités canadiennes. Il évalue d'abord ces politiques pour en établir les points communs et les différences. Puis, il examine comment leurs différentes perspectives, les politiques des droits de la personne et les codes de conduite étudiante, par exemple, peuvent affecter l'orientation et les résultats des réactions universitaires. La 
majorité des politiques consultées représentaient des codes de conduite et de discipline à l'intention des étudiants, des politiques de communication électronique et des politiques contre le harcèlement et la discrimination. Tandis que la plupart des politiques esquissaient des procédures de traitement des plaintes et identifiaient les sanctions possibles, très peu d'entre elles abordaient la prévention des comportements jugés inacceptables. Environ un tiers seulement faisaient référence aux cyber-comportements, ce qui sousentend qu'il existe un décalage entre les politiques en milieu universitaire et les technologies de l'information et de la communication qui font partie du quotidien des étudiants et des membres du corps professoral.

Information and communication technology (ICT) permeates daily life in university both within and outside of the learning environments. It has become part of the realities to which universities must adapt. While ICT can enhance learning environments and create unprecedented opportunities for students and faculty members, it also gives rise to certain problematic behaviours and situations, such as cyberbullying. In this study, cyberbullying is defined to include language or images conveyed through ICT that can defame, threaten, harass, bully, exclude, discriminate, stalk, disclose personal information, or contain offensive, vulgar, or derogatory comments. We adopt this broad definition in recognition of the lack of consensus that exists in the research literature of cyberbullying (see also Roberge, 2011, on varying definitions of the terms "bullying" and "harassment"). Many cyberbullying researchers rely on the definition of cyberbullying in Smith et al. (2008a, p. 376), which is an adaptation of the widely accepted definition of bullying in Olweus (1993, 1999). However, further analyses have suggested problems with such definitional criteria as repetition, power imbalance, and intent to harm when it comes to cyberbullying (see, for example, Dooley, Pyżalski, \& Cross, 2009; Grigg, 2010; Smith, 2012). Further, the juvenile connotation of the term "bullying" may seem not to apply to the adult members of the university community. However, we suggest that cyberbullying does in fact encompass many of the undesirable behaviours listed, without always transcending the legal threshold to be defined as harassment.

There has been an increase in anecdotal reports of instances of cyberbullying occurring in university classes, including in online courses, as well as in residences and on blogs and websites. Internationally, researchers have also begun documenting the prevalence and characteristics of cyberbullying and related behaviours at the university and college levels, which may be on a continuum with that which occurs in middle and secondary school (Adams \& Lawrence, 2011; Akbulut \& Eristi, 2011; Beran, Rinaldi, Bickham, \& Rich, 2012; Dilmaç, 2009; Finn, 2004; Kennedy \& Taylor, 2010; Molluzzo \& Lawler, 2012; Schenk \& Fremouw, 2012; Snell \& Englander, 2010; Turan, Polat, Karapirli, Uysal, \& Turan, 2011; Walker, Sockman, \& Koehn, 2011; Wensley \& Campbell, 2012; Zacchili \& Valerio, 2011; Zhang, Land, \& Dick, 2010).

This paper is part of a wider project examining cyberbullying at the university level. The main purpose of this research project is to investigate the extent, nature, form, and impact of cyberbullying among university students, between students and faculty, and between university colleagues, as well as to examine possible solutions. The present study 
examines the existing policies that are in place to address cyberbullying in universities in order to assess the commonalities and differences in such policies across Canada. Policy variations may emerge from the employment of differing lenses in their construction.

Policy can be understood and interpreted to have different meanings in different contexts. For our purposes, a policy sets out the values to be secured by certain actions taken; it often even specifies within itself, or in its related procedures, what those actions are. The values protected by a particular policy are often in tension (for example, individual rights versus collective rights), and the policy serves to establish a balance between them. When policy sets out the balance between the values in tension, its intent is established by systems to guide decision-making and actions about the behaviour or problem (Dye, 2005). An example of a high-level government policy document that sets out such balances in Canada is the Canadian Charter of Rights and Freedoms.

Since the authors are policy analysts and not lawyers, the focus upon policy here is by intent. Thus a legal analysis is beyond the scope of the present paper, even though it is obviously important to have clarity in that area as well. ${ }^{1}$ Although policy is not law, it sets the foundational value direction for the creation of law. Within educational institutions, it also establishes the direction for the development of procedure and practice. Policy at this level is also more proximal to the actual institutional operations. Ideally it is developed with input from institutional administrators as well as other key stakeholders such as faculty, staff, and students themselves.

Within the context of cyberbullying at the university level, policy refers to institutional directives governing conduct within and related to the university or its constituents. In this paper, we attempt to make meaning of having one type of policy or another governing cyberbullying behaviour. Thus, in cyberbullying, what can be seen as one set of values in tension is an individual's right to freedom of expression versus the right to freedom from harassment of those targeted (Brown, Jackson, \& Cassidy, 2006). For the latter group, the harassment may affect their quality of life, possibly even their safety.

\section{Context and Emerging Issues}

Cyberbullying research itself is relatively new, limited to approximately the past 10 to 12 years, with the vast majority of the work being published in the past five years. Research to date has mainly focused on students in middle or secondary school; a few studies have examined elementary school or college and university students (see Cassidy, Faucher, \& Jackson, 2013, for a comprehensive review of this literature). Some studies have begun to document the existence of cyberbullying in colleges and universities, but more research is needed to flesh out the extent, nature, form, and impact of cyberbullying at the university level.

The shift from secondary school to post-secondary is a transition on many levels. Students are seen no longer as their parents' dependants, but rather as young adults with individual responsibility and increased accountability. In contrast to the lower grades, where cyberbullying may be considered a developmental issue, a behaviour that children will outgrow, cyberbullying at university has a different tenor. In the emerging case law involving cyberbullying at the university level, for example, there appears to be less concern with the victim's rights, such as the right to security of person, than with the accused's rights, such as freedom of expression. ${ }^{2}$ Consistent with that approach, we have 
heard of no cases where a cyberbully has been banished from a university for his or her behaviour. Colleges and universities appear to have a different perspective on the behaviour and on the sanctions than do elementary and secondary schools.

This different conception is not unique to universities. For instance, bullying and cyberbullying are also evident within organizations and companies (Agervold, 2007; Cowie, Naylor, Rivers, Smith, \& Pereira, 2002; Lieber, 2010; Lim \& Cortina, 2005; Lutgen-Sandvik, Tracy, \& Alberts, 2007; MacIntosh, 2006; Privitera \& Campbell, 2009; WorkSafeBC, 2012). As adult behaviour, cyberbullying borders on the legal issue of harassment. At the university level, this behaviour is still predominantly referred to as cyberbullying (Akbulut \& Eristi, 2011; Dilmaç, 2009; Molluzzo \& Lawler, 2011; Schenk \& Fremouw, 2012; Snell \& Englander, 2010; Turan et al., 2011; Walker et al., 2011; Wensley \& Campbell, 2012; Zacchilli \& Valerio, 2011; Zhang et al., 2010), but other designations may also be appropriate. ${ }^{3}$

In terms of policy intent, we see differences as well. The university policy environment appears more legalistic and driven by due process. In contrast, policy at the lower school levels is more discretionary. In fact, in another study, we conducted interviews with educators and administrators in a middle school and a secondary school. The interviewees generally felt it would be a good idea to have a policy on cyberbullying; however, they expressed reservations about the policy being binding and taking away their discretionary power to handle situations as they saw fit (Faucher, Jackson, \& Cassidy, 2014). At university, the decision making as to which stream or which policy applies is the key to how a situation will be handled.

Some researchers have situated the issue of cyberbullying at the university level within the context of classroom incivility (DeSouza, 2010; Dickerson, 2005; Jones \& Scott, 2012; Lampman, Phelps, Bancroft, \& Beneke, 2009; Wildermuth \& Davis, 2012). Incivility at the university level refers to "the intentional behavior of students to disrupt and interfere with the teaching and learning process of others" (Morrissette, 2001, Introduction section, para. 2). This behaviour can be a passive form of aggression, somewhat ambiguous as to intent to harm. The perpetrator who is called out for his or her behaviour may easily deflect the accusation by suggesting that it was just a joke. However, incivility can also escalate into overt forms of aggression where the intent is quite clear.

The popularity of ICT and social media among youth is well known. Zacchilli and Valerio (2011) report that $92 \%$ of the college students they surveyed engaged in texting and that social networking is the most popular reason for accessing the Internet, even ahead of schoolwork. Other studies have documented considerable levels of hours of daily Internet use among undergraduate students (Turan et al., 2011; Walker et al., 2011) and very widespread mobile phone ownership (Turan et al., 2011).

The studies that have been published to date on cyberbullying at the university level suggest that cyberbullying is not limited to the lower grades. See Table 1 for a comparison of prevalence rates for cybervictimization and cyberperpetration. This table compares only studies that limited their inquiries to the cyberbullying experienced and perpetrated while in university and that relied on the repetition criteria in order to define acts of cyberaggression as cyberbullying. Preliminary analysis of 1,031 student surveys at one of the four Canadian universities in our wider project suggests similar levels of cyberbullying victimization. 
Table 1

Cyberbullying Prevalence Rates Found in Previous Studies of Undergraduate Students

\begin{tabular}{lccc}
\hline Study & $n$ & $\begin{array}{c}\text { Reported cyber- } \\
\text { victimization (\%) }\end{array}$ & $\begin{array}{c}\text { Reported cyberper- } \\
\text { petration (\%) }\end{array}$ \\
\hline Beran et al. (2012) & 1368 & 8.6 & 4.1 \\
Finn (2004) & 339 & $10-15$ & --- \\
Molluzzo \& Lawler (2012) & 121 & 7 & 10 \\
Schenk \& Fremouw (2012) & 799 & 8.6 & --- \\
Wensley \& Campbell (2012) & 528 & 11.6 & 3.8 \\
\hline
\end{tabular}

Walker et al. (2011) found that $11 \%$ of their 120 respondents acknowledged experiencing cyberbullying when asked outright. However, over 30\% responded in the affirmative when asked if they had experienced specific scenarios that the researchers felt were examples of cyberbullying. This discrepancy caused them to question whether some forms of cyberbullying may be legitimized as an acceptable part of social life in the online environment. This type of phenomenon was found in our own research as well. In focus groups we conducted with university students, the students initially expressed the belief that little or no cyberbullying was occurring at university. Then, as the discussion progressed, examples of cyberbullying behaviour emerged, causing the participants to reconsider their original assertions.

Very little is known about specific variables that correlate with cyberbullying at the university level. Gender differences have been examined in a few studies, with mixed results. Akbulut and Eristi (2011) found male students were more likely to be both victims and perpetrators. On the other hand, Dilmaç (2009) found that male students were more likely to report cyberbullying behaviour, whereas female students were more likely to report victimization. Sexuality and gender identity have also been examined in a few studies. Finn (2004) found that lesbian, gay, bisexual, and transgendered students were twice as likely as others to experience online harassment. Respondents in Molluzzo and Lawler (2012) identified gay, lesbian, and female persons as the main groups targeted by cyberbullying. Wensley and Campbell (2012) found that nonheterosexual respondents reported higher rates of traditional and cyberbullying victimization and perpetration, with statistically significant gender differences for nonheterosexual men and cyberbullying victimization. Policy-makers should consider factors such as gender and sexuality, as those variables impact responses and solutions. It may also be that other factors such as race, socioeconomic status, and disability need to be considered; however, there is a dearth of information about how those variables interact with cyberbullying behaviours.

In examining the relationship between earlier experiences of cyberbullying and those at the university level, researchers noticed some continuity. Adams and Lawrence (2011) discuss the "continuous effect" (p. 5) of earlier experiences with bullying. Beran et al. (2012) further note that the continuity is specific in terms of the type of harassment experienced in secondary school and in university. Students who were harassed in secondary school (online or offline) are much more likely to experience the same type of harassment in university. Similarly, those students who report engaging in cyberharassment in sec- 
ondary school are much more likely to report engaging in the same type of behaviour in university. A comparison by Wensley and Campbell (2012) of prevalence rates of traditional and cyber forms of bullying at university and in the lower grades found that rates of traditional bullying were lower among university students, but cyberbullying levels were similar between university and younger students. "These outcomes suggest that while traditional bullying decreases as adolescents move into university, cyberbullying may remain constant from the high school years" (Wensley \& Campbell, 2012, p. 652).

Jones and Scott (2012) examined the policies, processes, and programs in place at 27 Canadian universities in order to situate a case analysis of an instance of cyberbullying that occurred at a post-secondary institution in Canada. The main types of policies they examined included student codes of conduct, specific policies on bullying and/or harassment and cyberbullying, and policies on the use of information technology resources. They found that "most student conduct policies did not include a direct reference to cyberbullying. Where references were found, they typically consisted of one item in a list of unacceptable behaviors, and were not separately defined" (p. 174). Specific mentions of cyberbullying were more typically found in the acceptable use policies. The authors also assessed the accessibility and ease of navigation of the universities' websites for terms that someone might use to learn about cyberbullying-related policy. Eight of the 27 websites were easy to navigate, 11 were rated medium, and four were difficult. However, all the websites had directions for what to do and how to lodge a complaint. The authors highlight that policies require proper implementation in order to be effective, such as student training, staff training, initiatives in campus housing, and educative approaches coordinated by ombudsmen or other supportive departments. Less information was available about such programs, leading the authors to believe either that they are lacking or that the information about them is not easily accessible (Jones \& Scott, 2012).

\section{Current Study}

\section{Rationale}

In light of the realities of the cyberbullying context described above, the purpose of this research is to explore the current policy environment governing cyberbullying behaviour at the university level. To our knowledge, such studies have not yet been conducted, with one exception (Jones \& Scott, 2012). The findings from this part of our research will serve alongside those from our wider project documenting the extent, nature, form, and impact of cyberbullying at four Canadian universities. The findings from both parts of the research will assist us in considering how these policies might be improved to deal more effectively with emergent problems and their impacts. Basically, what does it mean for cyberbullying and responses at the university level when differing policies with differing policy intents are employed?

Preliminary analysis from the first wave of student and faculty surveys in our wider project shows that respondents rate "engaging with the university community in developing a strong anti-bullying policy" as one of the most popular solutions to cyberbullying at the university level. This solution is most often rated as number one by students among the 15 choices offered; for faculty, it comes second only to "developing a more respectful university culture when kind behaviour is modeled by all." Further, only a minority of respondents to both the faculty survey and the student survey agree that policies and 
procedures on student conduct, harassment, and bullying are clear, enforced, and/or effective, while many more simply "don't know."

Policy analytic/analysis theory orients our interpretation of the policies examined here. It has been argued that there are many theories that attempt to explain the complexities of the policy process (Surjadjaja \& Mayhew, 2011). In the present study, how a specific policy problem-cyberbullying at the university level-becomes initially framed as a policy problem can influence the subsequent outcomes or solutions "by serving as 'road maps' for actions" (Howlett \& Ramesh, 2003, p.127). The theoretical lens of ideas selected can come to define and construct the issue for action.

The decision about which lens to employ in the situation may be almost random in some settings, or highly structured by protocol in others. The possible options are many. Is it to be a harassment/discrimination lens (human rights), a student conduct and discipline lens, an electronic acceptable-use lens, a safe workplace (safe from violence) lens, or a freedom of expression lens?

\section{Method}

In this paper, we report on a scan of university policies that are relevant to the issue of cyberbullying. The scan was conducted from November 2011 to January 2012 using policy documents posted on the websites of 74 Canadian universities. ${ }^{4}$ The reliance on policies posted online resulted from our assessment that, in this day and age, policies that are not available online lack transparency. Students, staff, and faculty members require that degree of access to the policies that govern their lives at the university.

We first sought out different levels of administrative and operational policies of relevance to regulations of bullying or cyberbullying behaviours of university students, including such behaviours between students, by students toward instructional staff, and by instructional staff toward students. The search for policies was conducted in two ways. First, we attempted to locate a list, gazette, or repository of all university policy documents for each Canadian university and scoured these lists for policies that might be relevant to cyberbullying, judging by the policy titles. Second, we used the following search terms to generate or expand the list of potential policies: cyberbullying, bullying, human rights, appropriate conduct, ethical conduct, harassment, intimidation, slander, libel, threat, computer use, code of conduct, hazing, and discrimination. We then read the potential policies to determine whether they were in fact relevant. Policies were deemed relevant when they addressed cyberbullying or cyberharassment specifically or if they more broadly addressed behaviours that might be considered cyberbullying if occurring online without specifically referring to the online context as part of the scope of the policy. Relevant policies were indexed by university and by province.

Once we identified the relevant policies, we then scrutinized more closely the language within the policies. We established a set of parameters against which to evaluate the policies at the outset of the data collection, and it evolved as the data set grew. In the end, we coded each of the policies in a yes/no fashion to determine whether the policy:

- actually defines bullying/cyberbullying or other prohibited behaviours;

- sets out different types of behaviours that might constitute cyberbullying: for example, threats, slander, and violations of privacy (without necessarily defining each; using illustrations to explain); 
- situates these behaviours in the specific context of hazing;

- addresses discrimination or specifically mentions forms of bullying/cyberbullying, such as comments of a sexual nature or based upon gender, age, sexual orientation, disabilities, ethnic or cultural background, perceived physical abnormalities, and so on;

- describes any possible penalties or sanctions, including whether the policy makes a distinction between formal and informal modes of resolving a complaint;

- provides information about the complaint procedure to follow, or the office to contact when cyberbullying or bullying occurs;

- speaks to the issue of prevention or the university's role in raising the awareness of or "sensitizing" the university community on this issue; and

- specifies forms of harassment, bullying, or the like carried out using ICT (a cyberspecific policy).

\section{Findings}

We collected a total of 465 discrete policy documents from the websites of 74 Canadian universities. Table 2 indicates the number of universities scanned for relevant policies (not including those universities whose policies could not be obtained from the websites), along with the total number of policy documents from each province and territory and the average number of policies per university in each province and territory. The full list of universities is in the Appendix.

Table 2

Number of University Policies Relevant to Cyberbullying, by Province or Territory (as of January 2012)

\begin{tabular}{lccc}
\hline Province/territory & $\begin{array}{c}\text { Number of } \\
\text { universities }\end{array}$ & $\begin{array}{c}\text { Number of } \\
\text { policies }\end{array}$ & Average \\
\hline British Columbia & 11 & 67 & 6.1 \\
Alberta & 6 & 47 & 7.8 \\
Saskatchewan & 2 & 13 & 6.5 \\
Manitoba & 4 & 22 & 5.5 \\
Ontario & 20 & 144 & 7.2 \\
Quebec & 18 & 95 & $5 \cdot 3$ \\
New Brunswick & 4 & 29 & $7 \cdot 3$ \\
Nova Scotia & 5 & 29 & 5.8 \\
Prince Edward Island & 1 & 4 & 4 \\
Newfoundland and Labrador & 1 & 4 & 4 \\
Yukon & 1 & 6 & 6 \\
Northwest Territories & 1 & 5 & 5 \\
Total & 74 & 465 & 6.3 \\
\hline
\end{tabular}


Table 2 provides a distribution of policies by province and territory, which in itself shows some variations. While the totals suggest that each university has an average of just over six policies that would be relevant to issues of cyberbullying that might arise, there are variations among provinces and among universities. These variations notwithstanding, one point that must be noted is that all of the universities scanned have multiple policies that are or can be relevant to cyberbullying. As such, some degree of ambiguity over which policy to apply must exist.

The types of policies cover a range of areas. Three main types emerge. By far the most common relevant policies are those we categorized as codes of student conduct and discipline. The dominance of this category may be partly due to the broad inclusion of conduct policies in various areas of student life. We included undergraduate and graduate, nonacademic misconduct, library, and hazing policies as well as residence handbooks and athletic codes. These policies represent almost one third of all policies, with variations among individual provinces or territories: at the low end, approximately $24 \%$ in British Columbia and Nova Scotia; at the high end, 60\% in the Northwest Territories and 50\% in the Yukon and Manitoba. Only two of the universities surveyed had no policy (posted online) that fell into this category.

The second most common type of relevant policies was those pertaining to electronic communications (email, computer acceptable use, IT services, etc.), with $21.5 \%$ of all policies collected falling into this category. Again, some differences among provinces and territories exist, with British Columbia, Manitoba, New Brunswick, and Nova Scotia having close to $30 \%$ of their policies in this category. Only nine universities had no policy within this category.

The third most frequent type of policy that could be deemed relevant to cyberbullying was about harassment or discrimination (including sexual harassment, racism, hate speech, etc.). Overall, $17 \%$ of the policies collected were of this type, but variations by province were pronounced in this category as well. Quebec, New Brunswick, Nova Scotia, and Newfoundland and Labrador had more than $20 \%$ of their policies in this category, while Saskatchewan, Manitoba, and Prince Edward Island had fewer than 10\%. Only 14 universities surveyed had no harassment or discrimination policy.

Aside from these top three categories, the other policy types were far less common. We found policies pertaining to violence (safe workplace, campus), human rights and ethics, freedom of information, privacy, confidentiality, civility and respectful workplaces, other types of communication (such as phones, posters, freedom of expression), students with disabilities (including AIDS policies), human resources (employee/faculty codes of conduct), whistleblowing and safe disclosure, and charters of students' rights and responsibilities. It is noteworthy that although the incivility framework has been readily adopted as an applicable theoretical conceptualization for cyberbullying, it does not appear to be a dominant policy approach available to (or utilized by) universities for addressing the issue. See Table 3 for the numbers of each type of policies relevant to cyberbullying found at Canadian universities.

In observing the different types of policies that are in place and that may be deemed relevant to handling instances of cyberbullying within the university, we note once again that there are interesting variations among institutions and among provinces (see also Levinson \& Sutton, 2001). 
Table 3

Types of Policies Relevant to Cyberbullying at Universities in Canada

\begin{tabular}{lcc}
\hline Type of policy & $\begin{array}{c}\text { Number of } \\
\text { policies }\end{array}$ & $\begin{array}{c}\text { Percentage of } \\
\text { policies }\end{array}$ \\
\hline Codes of student conduct and discipline & 149 & 32.0 \\
Electronic communications & 100 & 21.5 \\
Harassment/discrimination & 79 & 17.0 \\
Violence & 34 & $7 \cdot 3$ \\
Human rights and ethics & 25 & 5.4 \\
Freedom of information/privacy & 20 & 4.3 \\
Civility/respectful workplace & 13 & 2.8 \\
Other communications & 10 & 2.2 \\
Students with disabilities/AIDS & 9 & 1.9 \\
Human resources & 8 & 1.7 \\
Charters of student rights and responsibilities & 7 & 1.5 \\
Whistleblower/safe disclosure & 6 & 1.3 \\
Other & 5 & 1.1 \\
Total & 465 & 100 \\
\hline
\end{tabular}

Deeper scrutiny of the policy language and content allowed us to consider and analyze the key components included within the policies, such as definitions, types of proscribed behaviours, whether the policies are specific to cyber exchanges, complaint procedures, specification of penalties, and whether awareness and prevention are part of the overall policy aims. This analysis provided points to anchor our discussion of the strengths and limitations of university policies governing cyberbullying. This exercise is necessary to the processes of policy development, implementation, and/or reform (Levinson \& Sutton, 2001; Smith et al., 2012).

\section{Analysis}

The analysis here is based on a scan of the policies and is not an in-depth reading or a content or discourse analysis. We are nonetheless in a position to report findings that have not been raised in the research literature to date. While Jones and Scott's analysis (2012) of university policies addressed the existing types of policies, processes, and programs at the top 27 universities rated by Maclean's magazine, our study extended to 74 Canadian universities offering bachelor's degrees. Our study confirms the findings of Jones and Scott using a wider representation of institutions, while also offering a more comprehensive understanding of the wide range of lenses potentially used to address cyberbullying in the post-secondary context and identifying gaps within the policy environment. A scan of the policies enabled us to draw attention to the policy environment that currently exists to govern cyberbullying at university; further questioning as to its adequacy can then take place. 
First, it is important to consider why certain types of policies appear more readily to incorporate cyberbullying into their mandates than others. The top three types of policies categorized above (codes of student conduct and discipline, electronic communications policies, and harassment/discrimination policies) represent over $70 \%$ of all university policies relevant to cyberbullying. This finding is consistent with those of Jones and Scott (2012). To conceive of cyberbullying as primarily a student conduct issue suggests that cyberbullying by faculty members and teaching or non-teaching staff is not yet on the radar at most institutions. Rather, the perspective adopted is that cyberbullying is conduct that is in conflict with the behavioural expectations of students. In fact, many of these codes make direct reference to other overarching pieces of legislation, such as the Canadian Charter of Rights and Freedoms and the Criminal Code of Canada. In keeping with the conduct code perspective, one would expect disciplinary sanctions to be attached to breaches of these codes. However, it is not clear that Canadian universities have dealt with cyberbullying in such a way. Our analysis did not extend to the actual approaches adopted in practice by universities; however, Jones and Scott (2012) found that educative, rather than punitive, measures were favoured as resolutions. Such an approach is consistent with viewing cyberbullying on a behavioural development continuum from the younger years.

The electronic communications policies situate the issue as one specific to the nature of online exchanges, thus differentiating cyberbullying from other forms of bullying. The solutions proposed within such policies are more closely linked to the use of technology, ultimately positioning access as a privilege with attendant responsibilities. Students who do not fulfill the responsibilities attached to the technology can then have their access denied. Given the pervasiveness of ICT and the overwhelming numbers of students who own cellphones and use them to send text messages and to access the Internet, we question the effectiveness of students being denied access to university technology services.

The harassment and discrimination policies are the third main lens through which cyberbullying can be viewed. These policies tend to use legalistic language, often citing existing legislation such as the Canadian Charter of Rights and Freedoms or provincial or territorial human rights acts. The policies are generally lengthy and detailed, often including a range of conflict resolution models for handling reports of harassment or discrimination. The use of such policies would also be in keeping with the research to date suggesting that cyberbullying is a gendered problem, which may also be impacted by sexuality (Akbulut \& Eristi, 2011; Dilmaç, 2009; Finn, 2004; Molluzzo \& Lawler, 2012; Wensley \& Campbell, 2012).

We also analyzed the content of the policies, looking for specific components mentioned above. While we did not attempt to score the content and quality of the policies as did Smith, Smith, Osborn, and Samara (2008b), Smith et al. (2012), and Roberge (2011), there were some points of comparison in that we assessed whether the policies provided definitions of bullying, made mention of prevention, and referenced cyberbullying specifically.

Providing a definition of the prohibited behaviour would seem to be a fundamental part of any policy that aims to address it. However, such an assumption is mistaken, since fewer than half $(45.4 \%)$ of the 465 policies included a definition of the prohibited behaviour, whether it be bullying, harassment, discrimination, or something else. On the other hand, some policies did include fairly elaborate and detailed definitions. For in- 
stance, Queen's University's Harassment/Discrimination Complaint Policy and Procedure (2000) provides a definitional framework, followed up with equally detailed definitions of sexual harassment, race and racism, heterosexism, and transphobia:

1. Queen's University recognizes that all members of the University Community have the right to be free from harassment and discrimination. This includes sexual harassment, harassment based on gender, race, ethnicity, religion, creed and sexual orientation or analogous grounds. Such harassment and discrimination has the purpose or effect of unreasonably interfering with an individual's or a group's work or academic performance, or of creating an intimidating, hostile or offensive working, living or academic environment. Individuals or groups who are not the direct target of the conduct in question may also suffer harassment and discrimination as a result of being present when such conduct takes place. ... It should be noted that personal/workplace harassment which is not based on one of the grounds enumerated above, is not covered under the following procedure.

2. Harassment and discrimination are exacerbated where:

a. submission to such conduct is made or threatened to be made either explicitly or implicitly a term or condition of an individual's employment, academic status or accreditation.

b. submission to or rejection of such conduct is used or threatened to be used as a factor in employment, academic status, grade, accreditation or other decisions affecting that individual or as the basis for any other form of advantage or reprisal.

Some policies included definitions that were somewhat less detailed, but still more informative than no definition at all. For example, Mount Allison University's Policy on Workplace Harassment (2011) provides the following definitions:

Personal harassment means any objectionable conduct, comment or display that is known or ought reasonably to be known to be offensive to an employee whether it occurs once or on a number of occasions....

Personal harassment may in some cases be discrimination on the grounds covered under the New Brunswick Human Rights Code, as may be amended from time to time. As of the date of this policy, these grounds are: race, color, religion, national origin, ancestry, place of origin, age, physical disability, mental disability, marital status, social condition, political belief or political activity.

While most policies did not specifically define cyberbullying, almost all (92.5\%) did provide examples of what types of behaviours fell under the scope of the particular policy (such as threats, slander, violations of privacy, harassing messages, or racist slurs). For instance, the University of Calgary's Electronic Communications Policy (2009), under section 4.14, prohibits: 
e) offensive, obscene or indecent images, data or any material that would violate the law;

f) defamatory material;

g) material that would by intent or otherwise harass the recipient;

h) material that would violate the privacy of others; or

i) messages that are anonymous or deliberately forged or that have deceptive address header information.

While the types of behaviours provided as examples are instructive, they are not allencompassing, and one can see how murky areas could be created by relying on examples rather than a full definition.

Of the types of behaviours listed, we singled out policies addressing hazing and discrimination as two types that were somewhat different forms of bullying or cyberbullying. Overall, $41.9 \%$ of the policies specifically addressed cyberbullying or bullying as a form of discrimination (for example, sending racist messages). Policies that included hazing within their scope were far fewer in number (10.1\%) and generally were separate policies from the more general codes of conduct or harassment policies.

We also paid particular attention to which proportion of these policies made specific reference to cyber behaviour (cyberbullying, online harassment, racist emails or web postings, inappropriate uses of ICT, etc.); $35.7 \%$ of the policies included such references. It seems that the policy environment has not yet caught up to the new reality of university students by recognizing the amount of time they spend online. For instance, Forston, Scotti, Chen, Malone, and Del Ben (2007), found that 90\% of the students they surveyed reported daily Internet use; about half met the criteria for Internet abuse and a quarter, the criteria for Internet dependence. Their review of the literature suggests that Internet use is increasing. Several studies have reported that the vast majority of college and university students are engaged in social networking online (see, for example, Kennedy \& Taylor, 2010; Zacchilli \& Valerio, 2011) and access the Internet on a daily basis, often for several hours (see, for example, Turan et al., 2011; Walker et al., 2011). Our initial analysis of student surveys in our broader study suggests that access to cellphones, text messaging, use of computers, and participation in social networking must be assumed to be daily features of most students' lives.

While policies instruct us about values to be secured, they can also suggest actions that might be taken. We found that the majority of the policies (77.2\%) we scanned did in fact tell readers the steps to be taken when a breach of the policy occurred. In some instances, the policies merely referred to an individual or office responsible for the enforcement of the policy and directed inquiries or complaints there. However, some policies were very detailed in setting out a complaint procedure and the steps to be taken by the various parties involved in order to resolve the situation. For example, the University of Winnipeg's Student Non-Academic Conduct and Discipline Policy (1994) lists the following range of applicable penalties: expulsion, suspension, exclusion from specific areas of the university, fines, restitution, conduct probation, written reprimands, community service, and the attachment of conditions prescribing future conduct. It then details procedures for 
resolving complaints under the policy, including how to initiate and conduct proceedings and appeals, how to establish a student discipline appeals committee when needed, and how to enforce and investigate.

Similarly, the majority of the policies (73.5\%) also set out specific sanctions or at least made reference to a range of penalties that might be applied, depending on the circumstances. In the growing research literature on cyberbullying, however, punishment is not considered a particularly effective approach, although it might be expected that university students are at an age when they should assume greater responsibility for their actions.

Unfortunately, prevention does not feature prominently in the policies aimed at cyberbullying at the university level. Only $21.7 \%$ of the policies referenced prevention in some way, with only a few, like the Université de Montréal's harassment policy (Politique contre le harcèlement, 2003) making it a priority. A few other policies highlighted the university's responsibility to raise awareness of cyberbullying, bullying, and harassment. Concordia University's Policy on Harassment, Sexual Harassment and Psychological Harassment (2011), for example, states as its first policy point:

1. Preventing harassing behaviour requires increased awareness of the impact that one's actions may have on others. The University firmly believes that prevention is the best tool for the elimination of such behaviour. Accordingly, the University intends to take all necessary steps to prevent that conduct from occurring, such as affirmatively raising the subject, expressing strong disapproval and developing methods to sensitize all concerned.

While prevention is a laudable focus, it remains to be seen whether and how policies such as this one are put into action. Several concrete ideas for prevention have emerged from our focus groups with university students. They advise that steps to raise awareness of the problem should take place early in a student's life at university, such as during the initial orientation sessions and on the first day of a course.

\section{Limitations and Future Directions}

While the aims of this policy scan were attained by the current analysis presented here, we are nonetheless compelled to consider this study's limitations and what more could be done to advance our understanding of university cyberbullying-related policies. First, having laid out what exists currently, we should now turn to the questions of how adequate the existing policies are, how well they have been implemented, and what processes are in place to review these policies and assess their effectiveness. This questioning should also extend to the differences that may exist between policy and practice. Second, comparative analyses between policies and between universities would be warranted. Although it exceeded the scope of this study, we did observe that there were high levels of similarity among policies found at different universities as well as important variations among policies within single institutions. Third, the present policy study (along with the additional analyses described in the first two points above) should be compared with a legal analysis of the rights and responsibilities of universities with respect to cyberbullying, in order to integrate and understand both policy and law environments. A primary aim would be to locate gaps, disjunctures or inconsistencies between the two frames of analysis in the making of meaning of cyberbullying behaviour and consider how to address them at the university level. 


\section{Conclusion}

This scan of university policies applicable to instances of cyberbullying at the university level reveals that a range of policies exist, though few are specific to cyberbullying. This overview draws attention to the ways in which different policy lenses can impact how a problem is framed, what decision-making processes are used, and what outcomes ensue.

While it is not the purpose of this paper, it is nonetheless important to consider what difference it may make to process incidents of cyberbullying through one type of policy as opposed to another. Different outcomes are anticipated when certain incidents are streamed into the mandate of one policy over another. For instance, to frame cyberbullying as a human rights issue suggests that a fundamental violation has occurred, whereas adopting a "civility" lens suggests that the violation is more one of manners. Similarly, to suggest that cyberbullying is a problem relating to electronic communication is quite different than framing it within the range of violent or potentially violent behaviours.

Clearly, there is no standardized response to cyberbullying, as evidenced through the multiple policies at each university that are applicable to this behaviour, with only about a third of these policies specifically addressing cyber behaviours. It is unclear how determinations are made to handle instances of cyberbullying under one policy over another in the absence of a policy specific to cyberbullying. It is important to consider how these decisions are made and the impact that they may have on both the purported victims and the perpetrators of cyberbullying. It appears that there should be greater standardization for the handling of such cases, as the wide range of applicable policies leads us to believe that universities may face liability issues if cyberbullying cases are not dealt with in a transparent and consistent manner. There is a need to set a balance between the values in tension when cyberbullying accusations are made; for example, the tensions between freedom of expression and security of the person may emerge with greater intensity as an issue in the future.

We also note that the mere existence of policies is not sufficient; there must be satisfactory implementation. As Jones and Scott's case study (2012) demonstrates, measures are needed to ensure that the university community is aware of the policies, that programs are in place to support their application, and that there is ongoing evaluation to ensure their adequacy to meet the realities of the situation.

Recommendations for improving the policy environment cannot be made at this point but rather will follow from an evaluation of the decision-making outcomes that result from the application of the existing policies in all their various perspectives.

\section{Notes}

1 The legal treatment of cyberbullying in Canada is rapidly changing within municipal, provincial, and federal governments, as these governments consider how they might better address cyberbullying through legislation (see Shariff \& Hoff, 2007).

2 The Court of Appeal in Alberta recently considered the use of social media by students at the university level to criticize their teachers, in Pridgen \& Pridgen $v$. University of Calgary, 2012 ABCA 139. The primary consideration was the rights to freedom of expression of twin brothers named Pridgen, who criticized their instructor on Facebook and were disciplined by the university for those actions. The Court of Appeal held that their freedom of expression rights had indeed been infringed. 
3 For example, cyberharassment is used by Beran et al., 2012, and Vance, 2010; cyberstalking is used by Alexy, Burgess, Baler, and Smoyak, 2005, and Finn, 2004; online harassment is used by Finn, 2004, and Kennedy \& Taylor, 2010.

4 Policies could not be located on the websites of these four universities: First Nations University, Saskatchewan; Laurentian University, Ontario; Royal Military College, Ontario; and Université Sainte-Anne, Nova Scotia. Policies were not sought in postsecondary institutions, such as colleges, where all or most programs offered were not for bachelor's degrees.

\section{Acknowledgements}

The authors wish to thank the research assistants who assisted with the data collection and coding. This paper stems from a broader research project funded by Social Sciences and Humanities Research Council Standard Research Grant ID 401-2011-1800.

\section{References}

Adams, F. D., \& Lawrence, G. L. (2011). Bullying victims: The effects last into college. American Secondary Education, 4O(1), 4-13.

Agervold, M. (2007). Bullying at work: A discussion of definitions and prevalence, based on an empirical study. Scandinavian Journal of Psychology, 48, 161-172. doi:10.1111/j.1467-9450.2007.00585.x

Akbulut, Y., \& Eristi, B. (2011). Cyberbullying and victimisation among Turkish university students. Australasian Journal of Educational Technology, 27(7), 1155-1170. Retrieved from http://www.ascilite.org.au/ajet/ajet27/akbulut.html

Alexy, E. M., Burgess, A. W., Baker, T., \& Smoyak, S. A. (2005). Perceptions of cyberstalking among college students. Brief Treatment and Crisis Intervention, 5(3), 279-289. doi:10.1093/brief-treatment/mhio20

Beran, T. N., Rinaldi, C., Bickham, D. S., \& Rich, M. (2012). Evidence for the need to support adolescents dealing with harassment and cyber-harassment: Prevalence, progression, and impact. School Psychology International, 33(5), 562-576. doi:10.1177/0143034312446976

Brown, K., Jackson, M., \& Cassidy, W. (2006). Cyber-bullying: Developing policy to direct responses that are equitable and effective in addressing this special form of bullying. Canadian Journal of Educational Administration and Policy, Issue 57. Retrieved from http://www.umanitoba.ca/publications/cjeap/articles/brown_jackson_cassidy.html

Cassidy, W., Faucher, C., \& Jackson, M. (2013). Cyberbullying among youth: A comprehensive review of current international research and its implications and application to policy and practice. School Psychology International, 34(6), 575-612. doi:10.1177/0143034313479697

Cowie, H., Naylor, P., Rivers, I., Smith, P. K., \& Pereira, B. (2002). Measuring workplace bullying. Aggression and Violent Behaviour, 7, 33-51.

DeSouza, E. R. (2010). Frequency rates and correlates of contrapower harassment in higher education. Journal of Interpersonal Violence, 48(11), 1-27. doi:10.1177/0886260510362878 
Dickerson, D. (2005). Cyberbullies on campus. University of Toledo Law Review, 37, 51.

Dilmaç, B. (2009). Psychological needs as a predictor of cyber bullying: A preliminary report on college students. Educational Sciences: Theory \& Practice, 9(3), 1307-1325.

Dooley, J. J., Pyżalski, J., \& Cross, D. (2009). Cyberbullying versus face-to-face bullying: A theoretical and conceptual review. Journal of Psychology, 217, 182-188. doi:10.1027/0044-3409.217.4.182

Dye, T. (2005). Understanding public policy. Upper Saddle River, NJ: Pearson Education/Prentice-Hall.

Faucher, C., Jackson, M., \& Cassidy, W. (2014). Cyberbullying among university students: Gendered experiences, impacts, and perspectives. Education Research International, 2014. doi:10.1155/2014/698545

Finn, J. (2004). A survey of online harassment at a university campus. Journal of Interpersonal Violence, 19, 468-483. doi:10.1177/0886260503262083

Forston, B. L., Scotti, J. R., Chen, Y.-C., Malone, J., \& Del Ben, K. S. (2007). Internet use, abuse, and dependence among students at a Southwestern regional university. Journal of American College Health, 56(2), 137-144. doi:10.3200/JACH.56.2.137-146

Grigg, D. W. (2010). Cyber-aggression: Definition and concept of cyberbullying. Australian Journal of Guidance and Counselling, 2O, 143-156. doi: 10.1375/ajgc.20.2.143

Howlett, M., \& Ramesh, M. (2003). Studying public policy: Policy cycles and policy subsystems (2nd ed.). Don Mills, ON: Oxford University Press.

Jones, J. C., \& Scott, S. (2012). Cyberbullying in the university classroom: A multiplicity of issues. In C. Wankel \& L. Wankel (Eds.), Misbehavior online in higher education (pp. 157-182). Bingley, UK: Emerald Publishing Group.

Kennedy, M. A., \& Taylor, M. A. (2010). Online harassment and victimization of college students. Justice Policy Journal, 7(1).

Lampman, C., Phelps, A., Bancroft, S., \& Beneke, M. (2009). Contrapower harassment in academia: A survey of faculty experience with student incivility, bullying, and sexual attention. Sex Roles, 6o, 331-346. doi:10.1007/s11199-008-9560-x

Levinson, B. A. U., \& Sutton, M. (2001). Introduction: Policy as/in practice-a sociocultural approach to the study of educational policy. In M. A. Sutton (Ed.), Policy as practice-Toward a comparative sociolegal analysis of educational policy. Westport, CT: Greenwood Publishing Group.

Lieber, L. (2010). Harassment goes viral-What can HR do to prevent it? Employment Relations Today, 37(2), 81-89.

Lim, S., \& Cortina, L. M. (2005). Interpersonal mistreatment in the workplace: The interface and impact of general incivility and sexual harassment. Journal of Applied Psychology, 9o(3), 483-496. doi:10.1037/0021-9010.90.3.483

Lutgen-Sandvik, P., Tracy, S. J., \& Alberts, J. K. (2007). Burned by bullying in the American workplace: Prevalence, perception, degree, and impact. Journal of Management Studies, 44(6), 838-857. doi:10.1111/j.1467-6486.2007.00715.x 
MacIntosh, J. (2006). Tackling workplace bullying. Issues in Mental Health Nursing, 27, 665-679. doi:10.1080/01612840600642984

Molluzzo, J. C., \& Lawler, J. P. (2012). A study of the perceptions of college students on cyberbullying. Information Systems Education Journal, 10(4), 84-109. Retrieved from http://isedj.org/2012-10/ISSN:1545-679X

Morrissette, P. J. (2001). Reducing incivility in the university/college classroom. International Electronic Journal for Leadership in Learning, 5(4). Retrieved from people.ucalgary.ca/ huartson/iejll/volume5/morrissette.html

Olweus, D. (1993). Bullying at school: What we know and what we can do. New York, NY: Blackwell.

Olweus, D. (1999). Sweden. In P. K. Smith, Y. Morita, J. Junger-Tas, D. Olweus, R. Catalano, \& P. Slee (Eds.), The nature of school bullying: A cross-national perspective (pp. 7-27). London, UK: Routledge.

Privitera, C., \& Campbell, M. (2009). Cyberbullying: The new face of workplace bullying? CyberPsychology and Behavior, 12, 395-400.

Roberge, G. D. (2011). Countering school bullying: An analysis of policy content in Ontario and Saskatchewan. International Journal of Education Policy \& Leadership, 6(5).

Schenk, A. M., \& Fremouw, W. J. (2012). Prevalence, psychological impact, and coping of cyberbully victims among college students. Journal of School Violence, 11(1), 21-37. do i:10.1080/15388220.2011.630310

Shariff, S., \& Hoff, D. L. (2007). Cyber bullying: Clarifying legal boundaries for school supervision in cyberspace. International Journal of Cyber Criminology, 1(1), 76-118.

Smith, P. K. (2012). Cyberbullying and cyber aggression. In S. R. Jimerson, A. Nickerson, M. J. Mayer, \& M. J. Furlong (Eds.), Handbook of school violence and school safety: International research and practice (2nd ed., pp. 93-103). New York, NY: Routledge.

Smith, P. K., Kupferberg, A., Mora-Merchan, J. A., Samara, M., Bosley, S., \& Osborn, R. (2012). A content analysis of school anti-bullying policies: A follow-up after six years. Educational Psychology in Practice, 28(1), 47-70. doi:10.1080/02667363.2011.639344

Smith, P. K., Mahdavi, J., Carvalho, M., Fisher, S., Russell, S., \& Tippett, N. (2008a). Cyberbullying: Its nature and impact in secondary school pupils. Journal of Child Psychology and Psychiatry, 49, 376-385. doi:10.1111/j.1469-7610.(2007).01846.x.

Smith, P. K., Smith, C., Osborn, R., \& Samara, M. (2008b). A content analysis of school anti-bullying policies: Progress and limitations. Educational Psychology in Practice, 24(1), 1-12. doi:10.1080/02667360701661165

Snell, P. A., \& Englander, E. K. (2010). Cyberbullying victimization and behaviors among girls: Applying research findings in the field. Journal of Social Sciences, 6(4), $510-514$.

Surjadjaja, C., \& Mayhew, S. (2011). Can policy analysis theories predict and inform policy change? Reflections on the battle for legal abortion in Indonesia. Health Policy and Planning, 1(26), 379-384. 
Turan, N., Polat, O., Karapirli, M., Uysal, C., \& Turan, S. G. (2011). The new violence type of the era: Cyber bullying among university students-Violence among university students. Neurology, Psychiatry and Brain Research, 17, 21-26. doi:10.1016/j. npbr.2011.02.005

Vance, J. W. (2010). Cyber-harassment in higher education: Online learning environments (Doctoral dissertation, University of Southern California). Retrieved from http://digitallibrary.usc.edu/cdm/compoundobject/collection/p15799coll127/id/309077/ $\mathrm{rec} / 19$

Walker, C. M., Sockman, B. R., \& Koehn, S. (2011). An exploratory study of cyberbullying with undergraduate university students. TechTrends, 55(2), 31-38.

Wensley,K.,\&Campbell,M.(2012). Heterosexualand nonheterosexualyounguniversity students' involvement in traditional and cyber forms of bullying. Cyberpsychology, Behavior, and Social Networking, 15(12), 649-654. doi:10.1089/cyber.2012.0132

Wildermuth, S., \& Davis, C. B. (2012). Flaming the faculty: Exploring root causes, consequences, and potential remedies to the problem of instructor-focused uncivil online student discourse in higher education. In C. Wankel \& L. Wankel (Eds.), Misbehavior online in higher education (pp. 379-404). Bingley, UK: Emerald Publishing Group.

WorkSafeBC(2012).Discussionpaper: Workplacebullying andharassment. Retrieved from http://www.worksafebc.com/regulation_and_policy/policy_consultation/assets/ pdf/BullyingHarassment.pdf

Zacchilli, T. L., \& Valerio, C. Y. (2011, March). The knowledge and prevalence of cyberbullying in a college sample. Journal of Scientific Psychology, 11-23.

Zhang, A. T., Land, L. P. W., \& Dick, G. (2010). Key influences of cyberbullying for university students. PACIS 2010 Proceedings. Paper 83. Retrieved from http://aisel. aisnet.org/pacis2010/83

\section{Contact Information}

Chantal Faucher

Centre for Education, Law \& Society

Simon Fraser University

cfaucher@sfu.ca

Chantal Faucher is a postdoctoral fellow with the Centre for Education, Law and Society at Simon Fraser University working on its local, national, and international projects related to cyberbullying at the middle school, secondary school, and university levels. She is also interested in media representations and the role of media in shaping public understanding of youth, crime, law, and justice.

Margaret Jackson is a professor emerita with the School of Criminology at Simon Fraser University, where she is also director of FREDA, an SFU centre undertaking research on violence against women and children. Her research interests include policy analysis, violence against women and children, bullying/cyberbullying, judicial attitudes, sentencing behaviour, risk assessment, and sociocultural factors impacting marginalized girls. 
Wanda Cassidy is an associate professor with the Faculty of Education at Simon Fraser University, where she is also the director of the Centre for Education, Law and Society. She works primarily in the areas of citizenship and human rights education. Key interests also include the ethics of care, conceptions of diversity and inclusion, and notions of social responsibility, legal literacy, marginalized youth, cyberbullying/cybercivility, and cultivating respectful school cultures. 